\title{
Easy ways for performing real-time holographic interferometry education
}

Ming-Wen Chang

Ming-Wen Chang, "Easy ways for performing real-time holographic interferometry education," Proc. SPIE 1603, Education in Optics, (1 March 1992); doi: $10.1117 / 12.57875$ 


\title{
EASY WAYS FOR PERFORMING REAL-TIME HOLOGRAPHIC INTERFEROMETRY EDUCATION
}

\author{
Ming-Wen Chang \\ Optical Sciences Center \\ National Central University \\ Chung-Li, Taiwan 32054, R.O.C.
}

\section{ABSTRACT}

Holographic interfercmetry experiments are very important in holography education. They are mainly divided into double-exposure, real-time and time average holographic interferometries. Because special equipments such as liquid gate and micropositioning base are very expensive, real-time holographic interfercmetry experiments which are thought to need those equipments are less popular in general laboratories. There are two well known ways to make real-time holographic interferometry experiments. One way is to replace developed film plate to its original place and another way is to develop film plate in-place. These two ways need the above mentioned very expensive equipments. We show some easy ways and use some simple equipments for film plate in-place developing to make the real-time holographic interferometry experiments possible in general laboratories. Comparisons and analyses of different ways are made. Also the diffraction efficiencies for different conditions are measured. We have the conclusion that movable tank processing in-place film plate developing is recamended.

\section{INTRODUCTION}

Holography education may be divided into broad realms ${ }^{1}$. Nowadays, in department of physics and department of electrical engineering of almost all universities and colleges, holography is taught. It even does in freshman physics of all science and engineering major. It also implemented in other discipline such as optics, laser, non-destructive testing or art. Sometimes it is implemented in the curriculum as an independent course. All these are in the college level. But holography education is also expanding into elementary, junior high and high schools world- wide. There are also a number of holography galleries, museums, and individual artists with labs who teach holography.

Costs of holography education facilities and equipments, low to high range over approximately one hundred times. With sand table and wooden mounts under self construction, people can make a variety of simple holograms with a minimum amount of effort and money ${ }^{2}$. As for making holographic interferometry, especially real-time holographic interfercmetry experiment, additional equipments are needed. It is beyond the ability for general laboratories to afford.

Holographic interferometry is very important in holography education because of its application in science and engineering. ${ }^{3-0}$ We report same easy ways by use simple equipments which can be afforded by every laboratories. One of the ways is even better than ways by using expensive equipments such as liquid gate and micropositioning base. 


\section{REAL-TIME HOLOGRAPHIC INTERFEROMETRY REQUIREMENT $^{7}$}

It is easier to explain real-time holographic interferometry with double exposure holographic interferometry than to explain it directly. A double exposure of the hologram is made on the same plate with two exposures. The first exposure is usually made with the object in an unstressed condition and the second is made with stress applied to the object and without disturbing the set-up. Then, in reconstruction there are two holographic patterns on the same plate. For real-time holographic interferometry, a hologram is shot, either developed and then replaced in the holder it was in for the exposure or developed in-place. It just means as in double exposure "without distrubing the set-up". When the object is illuminated as if to expose it for another shot, there are also two holographic patterns on the plate. One pattern will be the one you developed and the second pattern is created by the light you just turned on reflecting from the object still in its original position. The two patterns should match exactly if nothing moved and the plate is replaced exactly in its original spot. There are two ways by using different equipments to obtain the strict conditions:nothing moved and the plate is replaced exactly in its original position.

\subsection{In-place film plate development}

This is a good method of solving those problems of nothing moved and without disturbing the set-up. By using a "liquid gate" arrangement as shown in Fig 1, one can develop the hologram on the spot. It consists of a liquid gate and a film plate holder. Figure 1c shows the combination.

The liquid gate is normally made with high quality windows of BK-7 glass and polished to 1-2 wave flateness. Some times for precision, glass windows are polished to $\lambda / 4$. Film plates can be processed either by pouring photographic chemicals in from the top or by cycling chemicals from an elevated supply tank into the gate throuph a bottom drain/fill fitting. An overflow is safely vented through a separate fitting.

The set costs about two thousand US dollars. It is too expensive for general laboratories to aquire.

2.2. Replace the film plate in its original position

For example, a micropositioning base as shown in Fig. 2a is designed to provide stiction-free submicron positioning of a hologram in two orthogonal axes in the plane of the hologram. It is specifically designed for use with either the Fig.1b or Fig.2b Holographic Film Plate Holder. This assembly is mounted on a heavy duty magnetic base. The film plate in the film plate holder has nearly fixed position. The microposioning base can be adjusted to amend the not exact amount moved. EXACTLLY is a degree always difficult to obtain. This way is not recommended by the author. Besides, the cost is even higher than that of liquid gate arrangement.

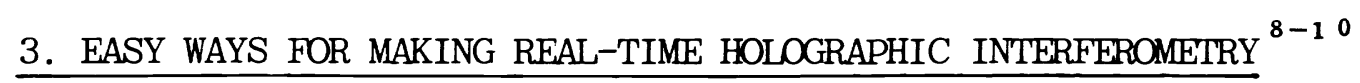

The cost of either of the above mentioned ways can not be afforded by most of the general labs. That is why real-time holographic interferometry is rarely made in most of the general labs. There are four easy ways with in-expensive equipments 
to accomplish the in-place developement successfully. They are:absorbent cotton or gauze wetting, use sprayer to spray, plastic bag liquid gate processing and movable tank processing.

For the first three ways, an iron or steel table or a thick iron or steel flat, a magnetic base, a post and a plate holder are necessary. The magnetic base, the post and the plate holder assembly is shown in Fig.3. For the way to do the movable tank processing, the plate holder can be mounted on a post and fixed upside down as shown in Fig.4.

\subsection{Absorbent cotton or gauze wetting}

In this way and the next, in between the table or flat and the magnetic base, an iron sheet box or a thin plastic sheet box is inserted. The thin plastic sheet does not shield the magnetic force. The magnetic base is still firmly attracted to the table or the flat. The boxes are biscuits containers. They are used here for accept the drained pholographic chemicals.

With well absorbed chemicals solutions, the cotton or gauze pad is attached to the plate emulsion side. With frequently replacing new pad, the plate is developed in-place.

\subsection{Use sprayer to spray}

Sprayers for plant and flower watering and for collar cleaning detergent can be used. Spray is made facing the emulsion side of the film plate. A plastic sheet or a sheet of glass should be hanged behind the film plate to block the stray chemicals.

\subsection{Plastic bag liquid gate processing}

Choosing a plastic bag of appropriate size to be large enough for containing the film plate holder and to be small enough to save volume for chemicals solutions. If the magnetic base and post are not too high, the bag can be fixed as for fixing the boxes. If the magnetic base and post are high, the bag should be fixed under the film plate holder. In this case, a hole with washer and screw should be installed to accept the post watertight. In all the cases, a hole connecting to a plastic tube is made at the bottom of the bag. Film plate can be processed by cycling chemicals from a tank which can be ascended to fill into the gate through the plastic tube and which can be descended to drain from the gate through the plastic tube too. When the chemicals are drained from the gate, the bag can be lowered to give the film plate no blockade.

\subsection{Movable tank processing}

With plate holder mounted on a post and fixed upside down as shown in Fig.4a, the plate can be processed by ascending the movable tank to a height to immerse the plate and to do the processing as shown in Fig.4b. After developing, the tank can be descended and taken away. 


\section{COMPARISIONS AND ANALYSES}

Replace the film plate in its original position is not recomended and not compared. Comparisons are made between glass window liquid gate and plastic bag liquid gate and between the four easy ways.

4.1.Comparison between glass window liguid gate and plastic bag liquid gate

Besides equipment costs, when the film plate is developed, glass window liquid gate remains with glass windows which diminishes the light intensity and causes aberrations. The plastic bag liguid gate leaves no blockade of light.

\subsection{Comparison between the four easy ways}

We simplify the names of the four easy ways as wetting, spraying, immersing and inversing. All these four easy ways leave no glass windows to block the light and to cause aberrations. By wetting and spraying, the film plate is not well processed. Immersing is better and inversing is the best. Inversing is also the most convenient way.

4.3. Measurements of diffraction efficiencies of all in-place development ways

The diffraction efficiences of all in-place development ways are measured. The results are shown in Table 1.

Tabe 1. Diffraction efficiences of all in-place development ways.

\begin{tabular}{|l|c|c|c|c|c|}
\hline \multirow{2}{*}{ Ways } & \multirow{2}{*}{ Wetting } & Spraying & \multicolumn{3}{|c|}{ Immersing } \\
\cline { 4 - 6 } & & & Glass Window & Plastic Bag & Inversing \\
\hline $\begin{array}{l}\text { Diffraction } \\
\text { Efficiencies }\end{array}$ & $27 \%$ & $32 \%$ & $49 \%$ & $41 \%$ & $51 \%$ \\
\hline
\end{tabular}

\subsection{Aberrations of window effects}

Windows are made of plane parallel plates. Even without parallelism problem, aberrations arise as incident axial pencil rays have convergence angle. The Seidel aberrations have spherical, coma, astigmatism, distortion. longitudinal colour and transverse colour, except no Petzval sum! ${ }^{1}$

It is not straight forward to calculate aberrations with two plane parallel plates each has parallelism problem and they together have parallelism problem also.

\section{DISCUSSION AND CONCLUSION}

Cost of equipments is one of the main factors to slow down the expanding of holography education. The reported easy ways with low cost equipments will help to promote holography education, or real-time holographic interfercmetry education. 
Also, there are no aberration problems as would arise from glass window liquid gate. We conclude that inversing is the best way for making real-time holographic interferometry.

\section{ACKNOWLEDGEMENT}

The author would like to express his appreciation for discussion with Dr.H.K.Liu of Jet Propulsion Lab. and Mr. Jin Wang of Institute of Optics and Eleetronics Academia Sinica and supports by National Science Council with contract NSC 80-D417-E-006-01.

\section{REFERENCES}

1. B. Kluepfel and F. Ross, eds., The holographic Market Place, 3rd ed., Ross Books, Berkley 1991.

2. F. Unterseher, J. Hansen and B. Schlesinger, Holography Handbook, Making Holograms the Easy Way, Ross Books, Berkley 1978.

3. R.K. Erf, Holographic Non-Destructive Testing, Academic Press, New Yark,1974.

4. E.R. Robertson and J.M. Harvey, eds., The Engineering Uses of Holography, Proceeding of the Symposium, University of Strathclyde, University Press, Cambridge, 1968.

5. G. Von Bally, ed., Holography in Medicine and Biology, Springer-Verlag, Berlin, 1979.

6. G.C. Willenbourg, "Holography and Holometry Applications in Dental Research," Proceedings of SPIE Vol.747, pp.51-56, 1978.

7. R.J. Collier, C.B. Burlkhardt and L.H. Lin, Optrcal Holography, Academic Press, New York, 1971.

8. W. Van Deelen, and P. Nisenson, "Mirror blank testing by real time holographic interfercmetry," Applied Optics, 8, 951-955, 1969.

9. P. Hariharan, and B.S. Ramprasad, 'Rapid in situ processing for real-time holographic interferometry", Journal of Physics E: Scientific Instruments,6,699$701,1973$.

10. P. Hariharan, 'Hologram interferometry:identification of the sign of surface displacements", Optica Acta,24,989-990,1977.

11. W.T. Welford, Aberrations of Optical Systems, Adam Hilger Ltd, Bristol and London, 1986. 


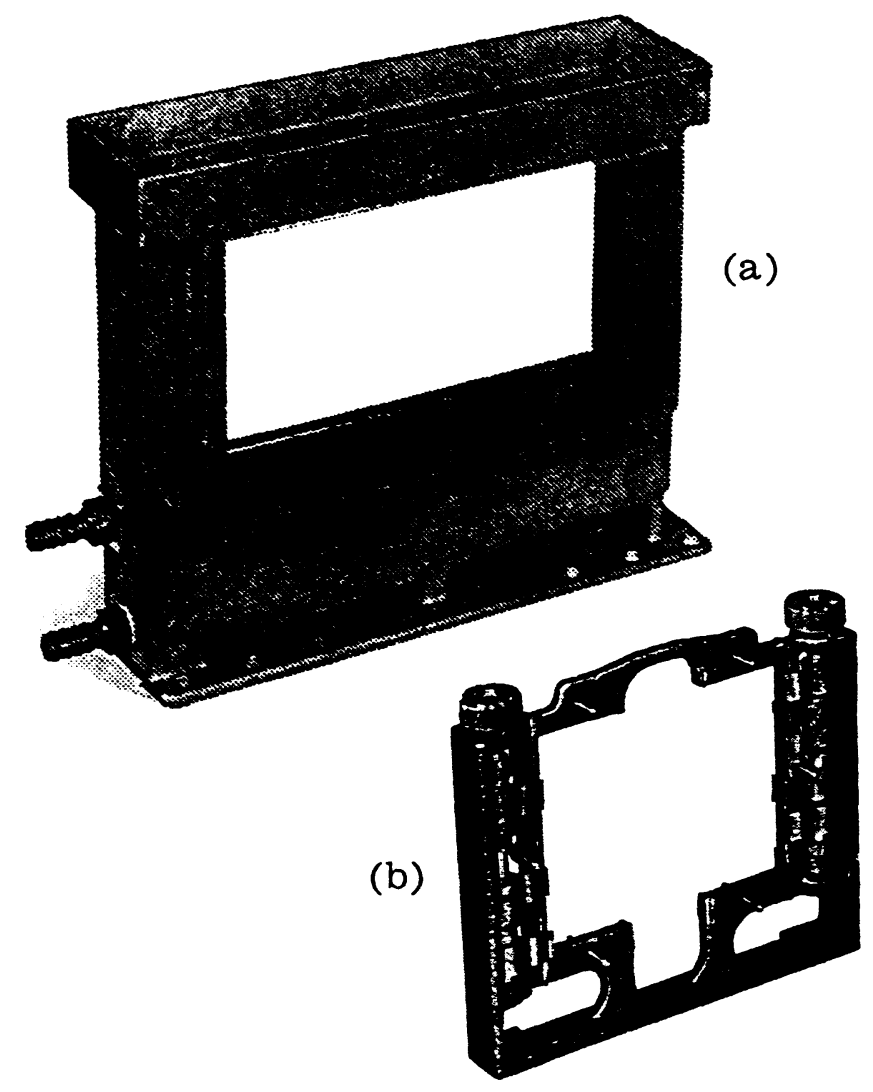

(c)

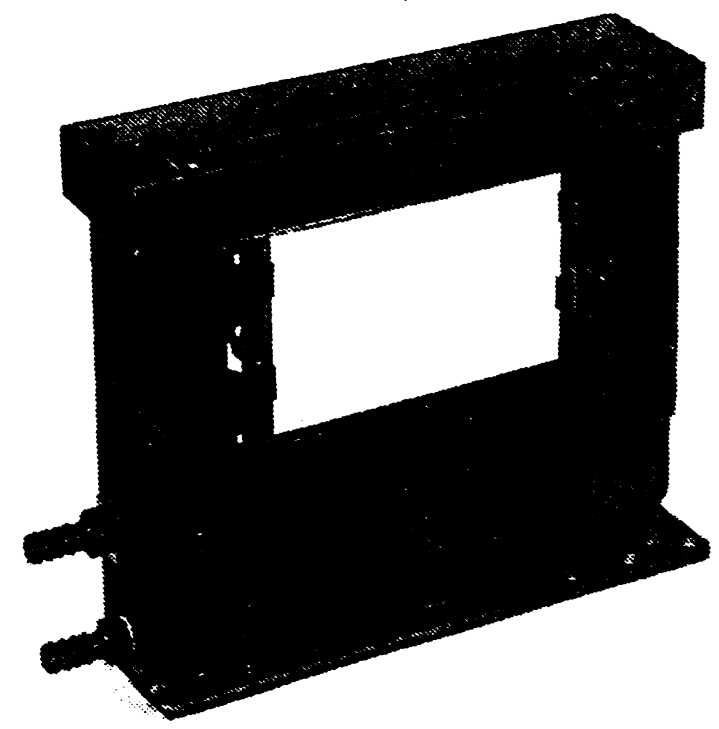

Fig.1. Liquid gate/Film plate holder/Processor

(a) Liquid gate, (b) Film plate holder

(c) Liquid gate processor.
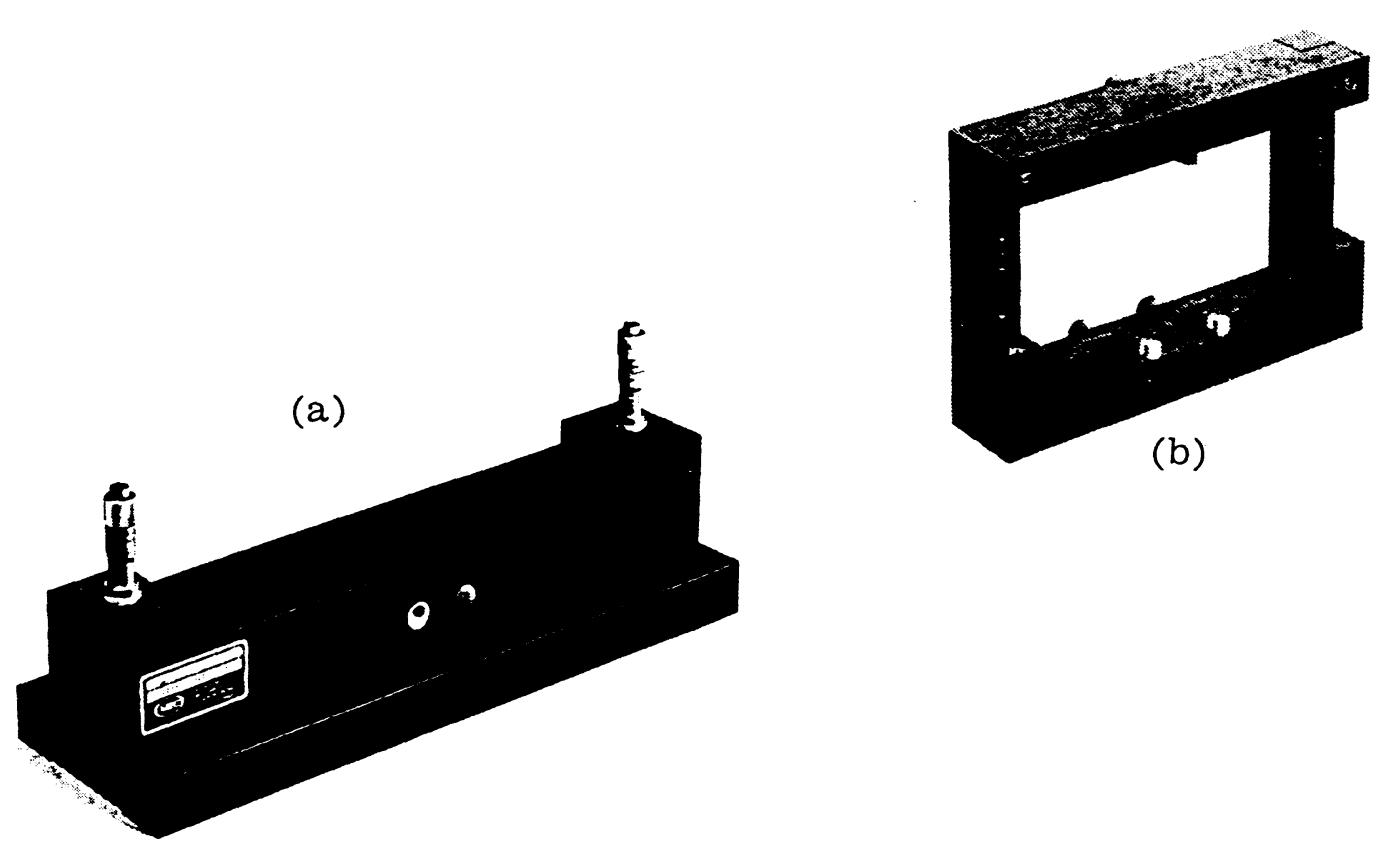

Fig. 2. Micropositioning base and film plate holder

(a) Micropositioning base, (b )Film blate holder.

456 / SPIE Vol. 1603 Education in Optics (1991)

Downloaded From: https://www.spiedigitallibrary.org/conference-proceedings-of-spie on 26 Apr 2023

Terms of Use: https://www.spiedigitallibrary.org/terms-of-use 


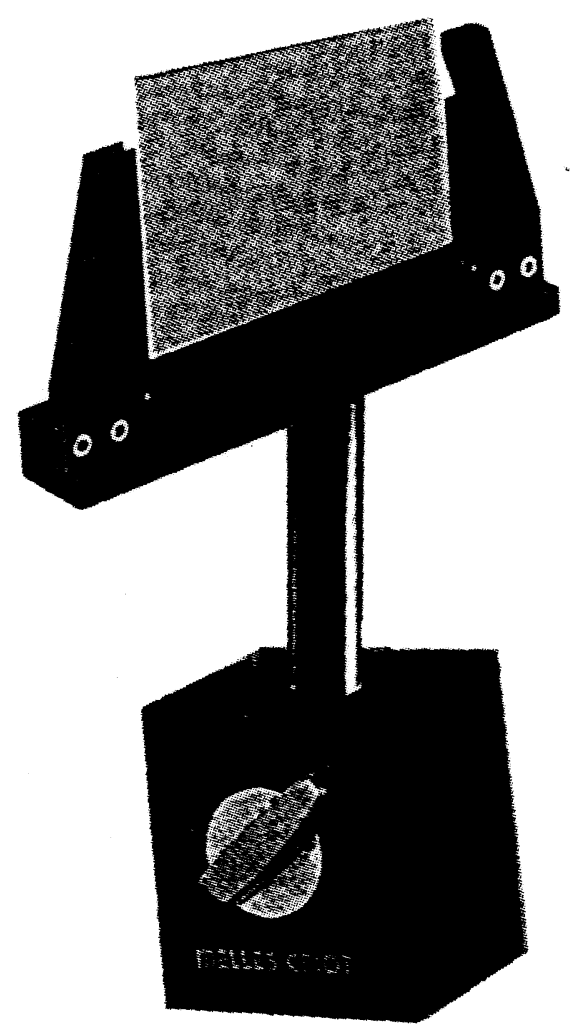

Fig. 3. The magnetic base, post and plate holder assembly.

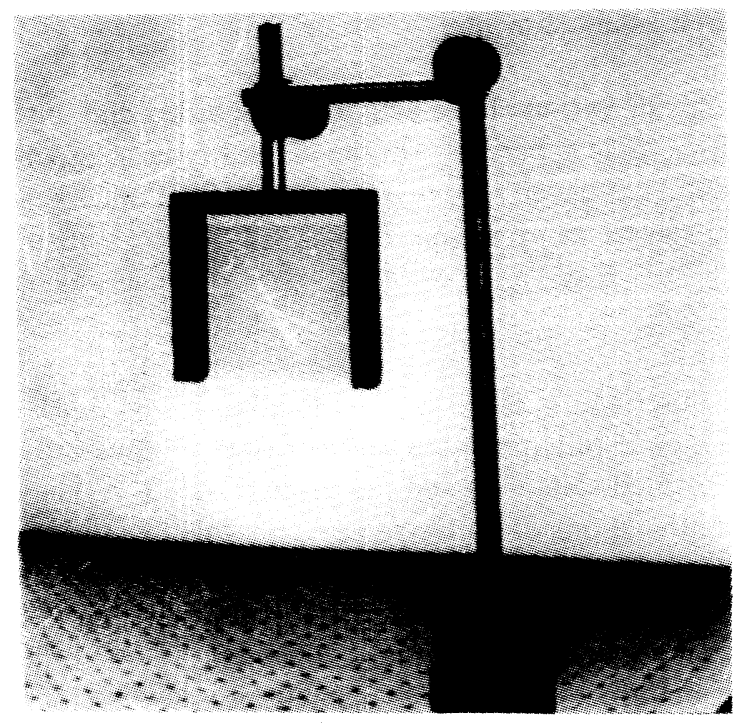

(a)

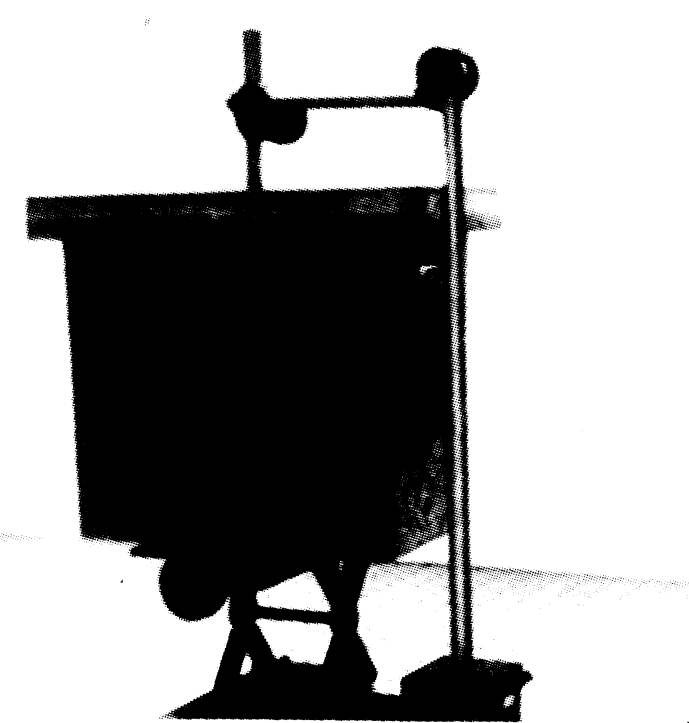

(b)

Fig. 4. Movable tank processing

(a) Plate holder inverse mounting

(b) Inverse mounted plate processing 